This is an author produced version of a paper published in Environmental Research. This paper has been peer-reviewed but does not include the final publisher proof-corrections or journal pagination.

Citation for the published paper:

Axmon, Anna

"Menarche in women with high exposure to persistent organochlorine pollutants in utero and during childhood."

Environ Res. 2006 Jan 31; [Epub ahead of print]

http://dx.doi.org/10.1016/j.envres.2005.12.014.

Access to the published version may require journal subscription.

Published with permission from: Elsevier 


\title{
Menarche in women with high exposure to persistent organochlorine pollutants in utero and during childhood
}

\author{
Anna Axmon \\ Division of Occupational and Environmental Medicine and Psychiatric Epidemiology, \\ Department of Laboratory Medicine, Lund University \\ Correspondence to: Anna Axmon, Division of Occupational and Environmental Medicine and \\ Psychiatric Epidemiology, University Hospital, SE-221 85 Lund, Sweden. Phone: +46-46- \\ 173960. Fax: +46-46-173669. E-mail: anna.axmon@med.lu.se
}

\begin{abstract}
In animal studies, exposure to persistent organochlorine pollutants (POPs) in utero and through mother's milk has been suggested to affect the onset of puberty. However, human studies are scarce and ambiguous. In the present study, information on age at menarche was collected from 545 women who had been brought up in a fishing village/family at the Swedish east coast, off the Baltic Sea, and therefore were assumed to have been exposed to POPs in utero, through breast feeding, and/or through dietary habits during their childhood. The average age at menarche for these women was compared to that of three referent groups: a) 1252 women who also had been brought up in a fishing village/family, but at the Swedish west coast where the fish had been considerably less contaminated, b) 634 women from the east coast, but who had not grown up in a fishing village/family, and c) 869 women from the west coast who had not grown up in a fishing village/family. Based on previous studies, all groups were regarded has having similar socio-economic circumstances. Data were analyzed using analysis of variance (ANOVA). In an attempt to account for variations in environmental concentrations of POPs over time, all analyses were adjusted for year of birth. Exposed women were found to be slightly older at menarche than referent women from the same coastal area (mean age 13.0 years vs. 12.8 years). No differences were found between the exposed women and the two other referent groups (mean age 13.0 years in all groups).
\end{abstract}

Key words: Fish consumption, sexual maturation, puberty, polychlorinated biphenyls, DDT

Financial support was received from the Swedish Medical Research Council, and the Swedish Research Council for Environment, Agricultural Sciences and Spatial Planning. The study was approved by the ethics committee at Lund University, Sweden. 


\section{INTRODUCTION}

Persistent organochlorine pollutants (POPs), such as dichloro-diphenyl-dichloroethylene (p,p'-DDE) and polychlorinated biphenyls (PCBs), are environmentally persistent chemicals which are lipophilic and tend to bioaccumulate. Even though the use of some of the chemicals has been banned in most countries, POPs can still be detected in human blood, adipose tissue and breast milk worldwide (Gladen et al. 1999, Wicklund-Glynn et al. 1996).

In Sweden, one of the major sources of POP exposure has for a long time been the consumption of fatty fish from the Baltic Sea, which is located off the east coast of the country (Ahlborg et al. 1995, Asplund et al. 1994, Svensson et al. 1991). Although current concentrations of POPs found in the Bothnian Bay (the most northern part of the Baltic Sea) are similar to those found off the Swedish west coast (Bignert et al. 1998), the Swedish National Food Administration still recommend restricted consumption of fatty fish from the Baltic Sea (http://www.slv.se).

Previous studies revealed that family members of professional Swedish east coast fishermen have been found to eat more fish from the Baltic Sea than the Swedish population in general (Hagmar et al. 1992, Rylander et al. 1995, 1996). The consumption of locally caught fish among fishermen's families from the west coast of Sweden is comparable to that of the fishermen's families on the Swedish east coast (Rylander et al. 1995). However, since the fish caught off the west coast is contaminated (Bergqvist et al. 1989, Bignert et al. 1998), the fishermen's families on the west coast were not as exposed as their counterparts on the east coast. Indeed, higher mean concentrations of the POP biomarker 2,2'4,4',5,5'hexachlorobiphenyl (CB-153) and p,p'-DDE has been found among east coast fishermen (297 ng/g lipid CB-153 and 433 ng/g lipid p,p'-DDE) than among west coast fishermen (190 ng/g lipid CB-153 and 241 ng/g lipid p,p’-DDE; Anna Rignell-Hydbom, personal communication). Thus, whereas east coast fishermen's families constitute an exposed population, the corresponding population on the west coast can be considered an appropriate referent group. Furthermore, it is assumed that the cohort members who have grown up in a fishing village and/or who are members of a fisherman's family have had a high fish consumption during their childhood and adolescence. Assuming that their mothers lived in the fishing village/family prior to the birth of their children as well as after, men and women who grew up in an east coast fishing village/family are likely to have been exposed in utero, as well as through lactation. In support of this, fishermen's wives who have grown up in a fishing village/family have been found to have higher plasma concentrations of B-153 than women who did not (Rylander et al. 1997).

In North America, consumers of fatty fish caught in the Great Lakes are highly exposed to POPs (Anderson et al. 1998, Gerstenberger et al. 2000, Hanrahan et al. 1999, Schwartz et al. 1983). Studies on women with high consumption of fish from the Baltic Sea or from the Great Lakes have suggested that high dietary exposure to POPs may cause damage to the female reproductive system, measured as time to pregnancy and delayed conception (Buck et al. 2000, McGuinness et al. 2001), as well as menstrual cycle length (Axmon et al. 2004, Mendola et al. 1997). Furthermore, increasing blood levels of PCB may be associated with decreasing age at menarche (Denham et al. 2005). Animal studies have found that in utero exposure to the PCB congener 2,2'4,4',5,5'-hexachlorobiphenyl (CB-153), but not the congener 3,3',4,4',5-pentachlorobiphenyl (CB-126), tend to delay onset of puberty in female goats (Lyche et al. 2004). Previous studies have suggested that POPs may interfere with the female reproductive system in both humans and animals. Rats exposed to Aroclor 1254 (a commercial mixture of PCBs) through mother's milk experienced delayed puberty (Sager and Girard 1994), whereas guinea pigs exposed to Clophen A50 (also a commercial mixture of PCBs) in utero and via mother's milk showed signs of delayed onset of sexual maturation, but 
no difference in age at first ovulation compared to unexposed controls (Lundkvist 1990). Although these studies indicate that POPs interfere with animal and human female reproductive systems, the extent of the interference is unknown. Furthermore, human studies regarding age at menarche and exposure to POPs are scarce. The purpose of the present study was to investigate whether dietary exposure to POPs in humans, indirectly estimated from growing up in an east coast fisherman's family, or east coast fishing village, was associated with increased age at menarche.

\section{MATERIALS AND METHODS}

\section{Study population, exposure and outcome}

In 1997, 2646 women who were, or had been, married to a professional Swedish fisherman (fishermen's wives), and who were born in 1945 or later, were sent a questionnaire regarding time to pregnancy and pregnancy outcome (Figure 1) (Axmon et al. 2000). Out of these, 795 women lived on the Swedish east coast and 1851 on the Swedish west coast. The questionnaire was returned by 505 (64 \%) east and 1090 (59 \%) west coast fishermen's wives.

Two years later, a similar questionnaire was sent out to 3264 women who were sisters, or half-sisters, to professional Swedish fishermen (fishermen's sisters), and who were born between 1945 and 1979 (Figure 1) (Axmon et al. 2002). For 2023 of these women, their brother lived on the west coast of Sweden, whereas 1241 were selected on the grounds that their brother was a fisherman on the east coast. The response rate was $55 \%$ ( $n=1103)$ among the west coast women, and $57 \%(n=709)$ among the east coast women.

Both questionnaires included two questions concerning the women's upbringing: "Did you grow up in a fisherman's family?” and "Did you grow up in a fishing village?”. By using cohort affiliation and information regarding upbringing in a fishing village/family, four exposure groups were established (Figure 1): East coast women who had grown up in a fishing village/family (exposed group), west coast women who had grown up in a fishing village/family (referent group 1), east coast women who had not grown up in a fishing village/family (referent group 2), and west coast women who had not grown up in a fishing village/family (referent group 3). It should be noted that cohort affiliation was determined by the current residence of the husband/brother, and that some women may have grown up on the opposite coast (see Discussion).

Both questionnaires contained the question "How old were you when you had your first menstruation?". For women who gave their answer in the form of an interval, the median of the interval was used. The majority of the women included in the study had provided this information (Figure 1). However, two west coast fishermen's sisters were excluded since they claimed that their menarche occurred when they were 44 and 50 years old, respectively.

\section{Non-respondents}

Non-respondent analyses have previously been performed on the fishermen's wives (Axmon et al. 2000) as well as the fishermen's sisters (Axmon et al. 2002). For the fishermen's wives, respondents and non-respondents to the questionnaire were similar with respect to age distribution, smoking habits and certain reproductive outcomes, such as having been pregnant at least once or having given birth to a low birth weight infant, or a child with malformations. Among the fishermen's sisters the non-respondents were older and had a lower degree of education than the respondents. Furthermore, within the non-respondent group, a higher percentage of women had never given birth. 


\section{Statistics}

Analysis of variance (ANOVA) was used to determine the difference in mean age at menarche between the exposed group and the three referent groups. The normality assumption was confirmed by residual plot analysis. All analyses were performed using SPSS for Windows 11.5.1.

Since the original questionnaires were designed to study time to pregnancy and pregnancy outcome, no questions on the woman's childhood were asked, apart from those determining exposure status. Thus, no adjustments for such factors were made. However, because the environmental contamination has decreased after the use of PCB and DDT was banned or restricted during the 1970's and 1980's, all models were adjusted for year of birth. Due to high correlations between year of birth and age ( $\mathrm{r}=0.99)$, as well as between year of birth and recall time ( $r=0.99)$, no adjustments were made for age or recall time.

Results are presented for the entire group of women, as well as separately for fishermen's wives and fishermen's sisters. The term "statistically significant" is used to denote a p-value less than 0.05 .

\section{RESULTS}

The mean age at menarche was 13.0 years for all four groups of west coast women, as well as for both exposed groups (Table 1). For east coast women who had not grown up in a fishing village/family, the mean age was slightly lower (12.8 years for the fishermen's wives and 12.9 years for the fishermen's sisters).

When comparing the three referent groups to the exposed groups, no pattern emerged with respect to the two west coast groups (Table 1). The east coast women who had not grown up in a fishing village/family were younger at menarche than the exposed group, but this difference was statistically significant only when fishermen's wives and fishermen's sisters were analyzed together.

There was no obvious time trend with respect to age at menarche for the exposed group or the referent groups (Figure 2).

\section{DISCUSSION}

The present study did not indicate a relation between a high POP exposure in utero and through breast milk or food intake during childhood and age at menarche.

All women included in the study were selected based on their relation to a professional fisherman. With respect to the fishermen, cohort affiliation was determined by the Swedish coastal area were they were registered. Their wives and sisters were then assigned to the same cohort as the fisherman to whom they were related. Thus, misclassification of exposure could occur among the fisherman's wives if a woman had grown up on the opposite coast to where she lived during her adult life, and among the fishermen's sisters if the fisherman himself grew up on the opposite coast to where he worked during his adult life. Such misclassification would most likely bias the results towards the null. However, previous studies have found that the fishermen's families cohorts are stable with respect to residence (Axmon et al. 2002). Furthermore, it is unlikely that the women would not be able to recall whether they had grown up in a fisherman's family or in a fishing village. Therefore, misclassification of exposure should not be large enough to account for the lack of association between POP exposure and age at menarche found in the present study.

Previous studies have found a low reliability of long-term recall of fish intake in the fishermen's families cohorts (Rylander et al. 1998). Thus, asking each woman about her 
consumption of fatty fish during her childhood would not necessarily have provided a better measure of exposure than having grown up in a fishing village/family.

The women in the present study were born between 1945 and 1979. Assuming that their age at menarche was correctly provided, the median recall time was 30 years (range 4-45 years). However, menarche is a significant developmental event which is readily recalled by a majority of women regardless of age (Casey et al. 1991, Golub and Catalano 1983, Must et al. 2002), and the results are therefore not expected to be influenced by recall bias with respect to the outcome.

Since the end of the 1960's, when the Baltic Sea environment was found to be severely polluted by DDT and PCB, continuous temporal monitoring of contaminants has been conducted in Sweden (Bignert et al. 1998). Levels of DDT have been decreasing since the program started in 1968, as have levels of PCBs since 1976. The contamination level of the Baltic Sea prior to 1968 has not been documented. However, due to bioaccumulation and slow metabolization of DDT and PCB, it is fair to assume that the concentrations of these compounds increased from the time they were introduced until the time their use was restricted. To account for these changes in environmental concentrations, all analyses were adjusted for the women's year of birth.

Because the questionnaires, through which the information on exposure and outcome was collected, were mainly focused on reproductive outcomes in mature women, no data were collected on life style and background factors for the women's childhood and adolescence. A Swedish study relating to the time period of interest in the present study found no difference in mean age at menarche between girls from different social groups, defined by the father's or the mother's occupation (Furu 1976). Moreover, the east and west coast fishermen's families have previously been found to be comparable with regard to socio-economic factors (Rylander et al. 1995). Therefore, failing to adjust for socio-economic factors would not be expected to have biased the results.

Other factors that have been suggested to result in earlier menarche are increased weight and height (Maclure et al. 1991, Merzenich et al. 1993, Moisan et al. 1990). As adults, the east coast fishermen's wives have been found to have a slightly higher BMI than those from the west coast (Wallin et al. 2004). If this also was the case during childhood and adolescence, and for the fishermen's sisters, the east coast women would be expected to be younger at menarche than the west coast women. The lack of association between age at menarche and POP exposure in the present study could then be a result of a positive and a negative effect cancelling each other out.

From the original cohorts of fishermen's wives and fishermen' sisters only 55\% were included in the present study. The major loss occurred when the women decided not to answer the questionnaires on fertility. Non-respondents analyses for both fishermen's wives and fishermen's sisters have been published previously (Axmon et al. 2000, 2002). In this study, it was concluded that there may be a selection bias with respect to fecundity. If fecundity is related to age at menarche, there may also be a selection bias in the present study. However, the mean age at menarche was 13.0 years, which is similar to the mean age (13.1 years) found among women from the Swedish capital in 1967 (Furu 1976). Thus, selection bias with respect to age at menarche is most likely not a major problem in the present study.

Studies investigating the possible relation between POPs and human sexual maturation are scarce. In a recent cross-sectional study of Akwesasne Mohawk Girls, a high concentration of blood PCB indicated a higher probability of having reached menarche, i.e. that highly exposed females tended to be younger at menarche (Denham et al. 2005). Contradictory to this study, Vasiliu et al (Vasiliu et al. 2004) found that in utero exposure to DDE, but not PCB, resulted in reduced age at menopause. However, this effect was no longer statistically significant when adjusted for BMI. Adding the information provided by the 
present study, the results are indeed ambiguous and further studies need to be carried out to entangle the possible relation between exposure to POPs and age at menarche.

\section{ACKNOWLEDGEMENTS}

The author is indebted to professor Lars Hagmar for valuable discussions.

\section{REFERENCES}

Ahlborg, U.G., Lipworth, L., Titus-Ernstoff, L., Hsieh, C.C., Hanberg, A., Baron, J., Trichopoulos, D., Adami, H.O., 1995. Organochlorine compounds in relation to breast cancer, endometrial cancer, and endometriosis: an assessment of the biological and epidemiological evidence. Crit Rev Toxicol 25, 463-531.

Anderson, H.A., Falk, C., Hanrahan, L., Olson, J., Burse, V.W., Needham, L., Paschal, D., Patterson, D., Jr., Hill, R.H., Jr., 1998. Profiles of Great Lakes critical pollutants: a sentinel analysis of human blood and urine. The Great Lakes Consortium. Environ Health Perspect 106, 279-89.

Asplund, L., Svensson, B.G., Nilsson, A., Eriksson, U., Jansson, B., Jensen, S., Wideqvist, U., Skerfving, S., 1994. Polychlorinated biphenyls, 1,1,1-trichloro-2,2-bis(p-chlorophenyl)ethane (p,p'-DDT) and 1,1-dichloro-2,2-bis(p-chlorophenyl)-ethylene (p,p'-DDE) in human plasma related to fish consumption. Arch Environ Health 49, 477-86.

Axmon, A., Rylander, L., Strömberg, U., Hagmar, L., 2000. Time to pregnancy and infertility among women with a high intake of fish contaminated with persistent organochlorine compounds. Scand J Work Environ Health 26, 199-206.

Axmon, A., Rylander, L., Strömberg, U., Hagmar, L., 2002. Female fertility in relation to the consumption of fish contaminated with persistent organochlorine compounds. Scand J Work Environ Health 28, 124-32.

Axmon, A., Rylander, L., Strömberg, U., Hagmar, L., 2004. Altered menstrual cycles in women with a high dietary intake of persistent organochlorine compounds. Chemosphere 56, 813-9.

Bergqvist, P., Bergek, S., Hallbäck, H., Rappe, C., Slorach, S., 1989. Dioxins in cod and herring from the seas around Sweden. Chemosphere 19, 513-6.

Bignert, A., Olsson, M., Persson, W., Jensen, S., Zakrisson, S., Litzen, K., Eriksson, U., Haggberg, L., Alsberg, T., 1998. Temporal trends of organochlorines in Northern Europe, 1967-1995. Relation to global fractionation, leakage from sediments and international measures. Environ Pollut 99, 177-98.

Buck, G.M., Vena, J.E., Schisterman, E.F., Dmochowski, J., Mendola, P., Sever, L.E., Fitzgerald, E., Kostyniak, P., Greizerstein, H., Olson, J., 2000. Parental consumption of contaminated sport fish from Lake Ontario and predicted fecundability. Epidemiology 11, 388-93. 
Casey, V.A., Dwyer, J.T., Coleman, K.A., Krall, E.A., Gardner, J., Valadian, I., 1991. Accuracy of recall by middle-aged participants in a longitudinal study of their body size and indices of maturation earlier in life. Ann Hum Biol 18, 155-66.

Denham, M., Schell, L.M., Deane, G., Gallo, M.V., Ravenscroft, J., DeCaprio, A.P., 2005. Relationship of lead, mercury, mirex, dichlorodiphenyldichloroethylene, hexachlorobenzene, and polychlorinated biphenyls to timing of menarche among Akwesasne Mohawk girls. Pediatrics 115, e127-34.

Furu, M., 1976. Menarcheal age in Stockholm girls, 1967. Ann Hum Biol 3, 587-90.

Gerstenberger, S.L., Dellinger, J.A., Hansen, L.G., 2000. Concentrations and frequencies of polychlorinated biphenyl congeners in a Native American population that consumes Great Lakes fish. J Toxicol Clin Toxicol 38, 729-46.

Gladen, B.C., Schecter, A.J., Papke, O., Shkyryak-Nyzhnyk, Z.A., Hryhorczuk, D.O., Little, R.E., 1999. Polychlorinated dibenzo-p-dioxins, polychlorinated dibenzofurans, and coplanar polychlorinated biphenyls in breast milk from two cities in Ukraine. J Toxicol Environ Health A 58, 119-27.

Golub, S., Catalano, J., 1983. Recollections of menarche and women's subsequent experiences with menstruation. Women Health 8, 49-61.

Hagmar, L., Linden, K., Nilsson, A., Norrving, B., Åkesson, B., Schütz, A., Möller, T., 1992. Cancer incidence and mortality among Swedish Baltic Sea fishermen. Scand J Work Environ Health 18, 217-24.

Hanrahan, L.P., Falk, C., Anderson, H.A., Draheim, L., Kanarek, M.S., Olson, J., 1999. Serum PCB and DDE levels of frequent Great Lakes sport fish consumers-a first look. The Great Lakes Consortium. Environ Res 80, S26-S37.

Lundkvist, U., 1990. Clinical and reproductive effects of Clophen A50 (PCB) administered during gestation on pregnant guinea pigs and their offspring. Toxicology 61, 249-57.

Lyche, J.L., Oskam, I.C., Skaare, J.U., Reksen, O., Sweeney, T., Dahl, E., Farstad, W., Ropstad, E., 2004. Effects of gestational and lactational exposure to low doses of PCBs 126 and 153 on anterior pituitary and gonadal hormones and on puberty in female goats. Reprod Toxicol 19, 87-95.

Maclure, M., Travis, L.B., Willett, W., MacMahon, B., 1991. A prospective cohort study of nutrient intake and age at menarche. Am J Clin Nutr 54, 649-56.

McGuinness, B.M., Buck, G.M., Mendola, P., Sever, L.E., Vena, J.E., 2001. Infecundity and consumption of polychlorinated biphenyl-contaminated fish. Arch Environ Health 56, 250-3.

Mendola, P., Buck, G.M., Sever, L.E., Zielezny, M., Vena, J.E., 1997. Consumption of PCBcontaminated freshwater fish and shortened menstrual cycle length. Am J Epidemiol 146, $955-60$. 
Merzenich, H., Boeing, H., Wahrendorf, J., 1993. Dietary fat and sports activity as determinants for age at menarche. Am J Epidemiol 138, 217-24.

Moisan, J., Meyer, F., Gingras, S., 1990. A nested case-control study of the correlates of early menarche. Am J Epidemiol 132, 953-61.

Must, A., Phillips, S.M., Naumova, E.N., Blum, M., Harris, S., Dawson-Hughes, B., Rand, W.M., 2002. Recall of early menstrual history and menarcheal body size: after 30 years, how well do women remember? Am J Epidemiol 155, 672-9.

Rylander, L., Dyremark, E., Strömberg, U., Östman, C., Hagmar, L., 1997. The impact of age, lactation and dietary habits on PCB in plasma in Swedish women. Sci Total Environ 207, 5561.

Rylander, L., Stromberg, U., Hagmar, L., 1998. Agreement between reported fish consumption obtained by two interviews and its impact on the results in a reproduction study. Eur J Epidemiol 14, 93-7.

Rylander, L., Strömberg, U., Hagmar, L., 1995. Decreased birthweight among infants born to women with a high dietary intake of fish contaminated with persistent organochlorine compounds. Scand J Work Environ Health 21, 368-75.

Rylander, L., Strömberg, U., Hagmar, L., 1996. Dietary intake of fish contaminated with persistent organochlorine compounds in relation to low birthweight. Scand J Work Environ Health 22, 260-6.

Sager, D.B., Girard, D.M., 1994. Long-term effects on reproductive parameters in female rats after translactational exposure to PCBs. Environ Res 66, 52-76.

Schwartz, P.M., Jacobson, S.W., Fein, G., Jacobson, J.L., Price, H.A., 1983. Lake Michigan fish consumption as a source of polychlorinated biphenyls in human cord serum, maternal serum, and milk. Am J Public Health 73, 293-6.

Svensson, B.G., Nilsson, A., Hansson, M., Rappe, C., Akesson, B., Skerfving, S., 1991. Exposure to dioxins and dibenzofurans through the consumption of fish. N Engl J Med 324, 8-12.

Wallin, E., Rylander, L., Hagmar, L., 2004. Exposure to persistent organochlorine compounds through fish consumption and the incidence of osteoporotic fractures. Scand J Work Environ Health 30, 30-5.

Vasiliu, O., Muttineni, J., Karmaus, W., 2004. In utero exposure to organochlorines and age at menarche. Hum Reprod 19, 1506-12.

Wicklund-Glynn, A., Atuma, S., Darnerud, P., Zettermark, S., Aune, M., Lundkvist, B., Wolk, A., Vessby, B., Adami, H.-O., 1996. PCBs and chlorinated pesticides in blood from Swedish men. 16th Symposium on Halogenated Environmental Organic Pollutants, Amsterdam, The Netherlands. 
Table 1. Menarche among wives and sisters of professional fishermen on the Swedish east (exposed) and west (referents) coasts. Comparisons between east and west coast are made using linear regression. Difference in means (B) are presented with 95\% confidence intervals (CI).

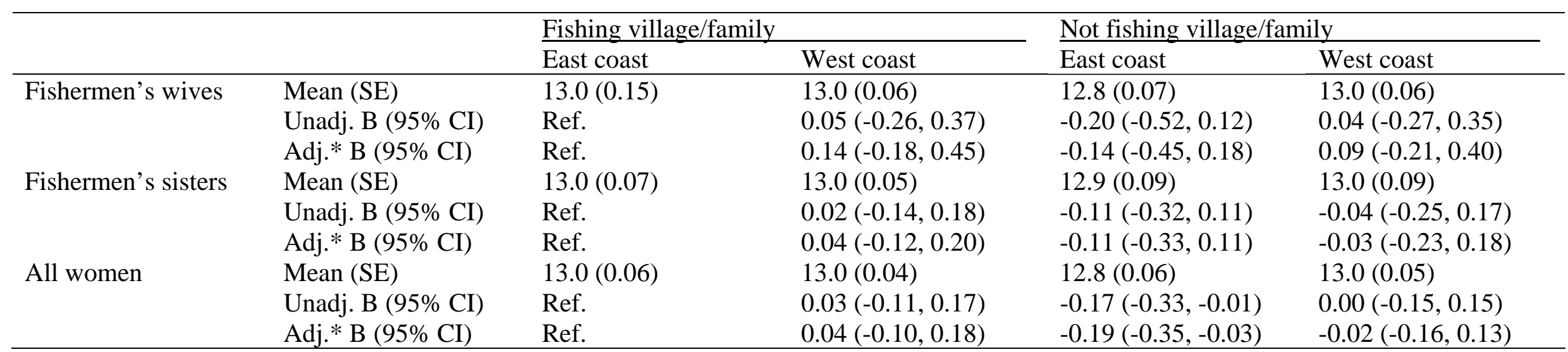

* Adjusted for year of birth. 


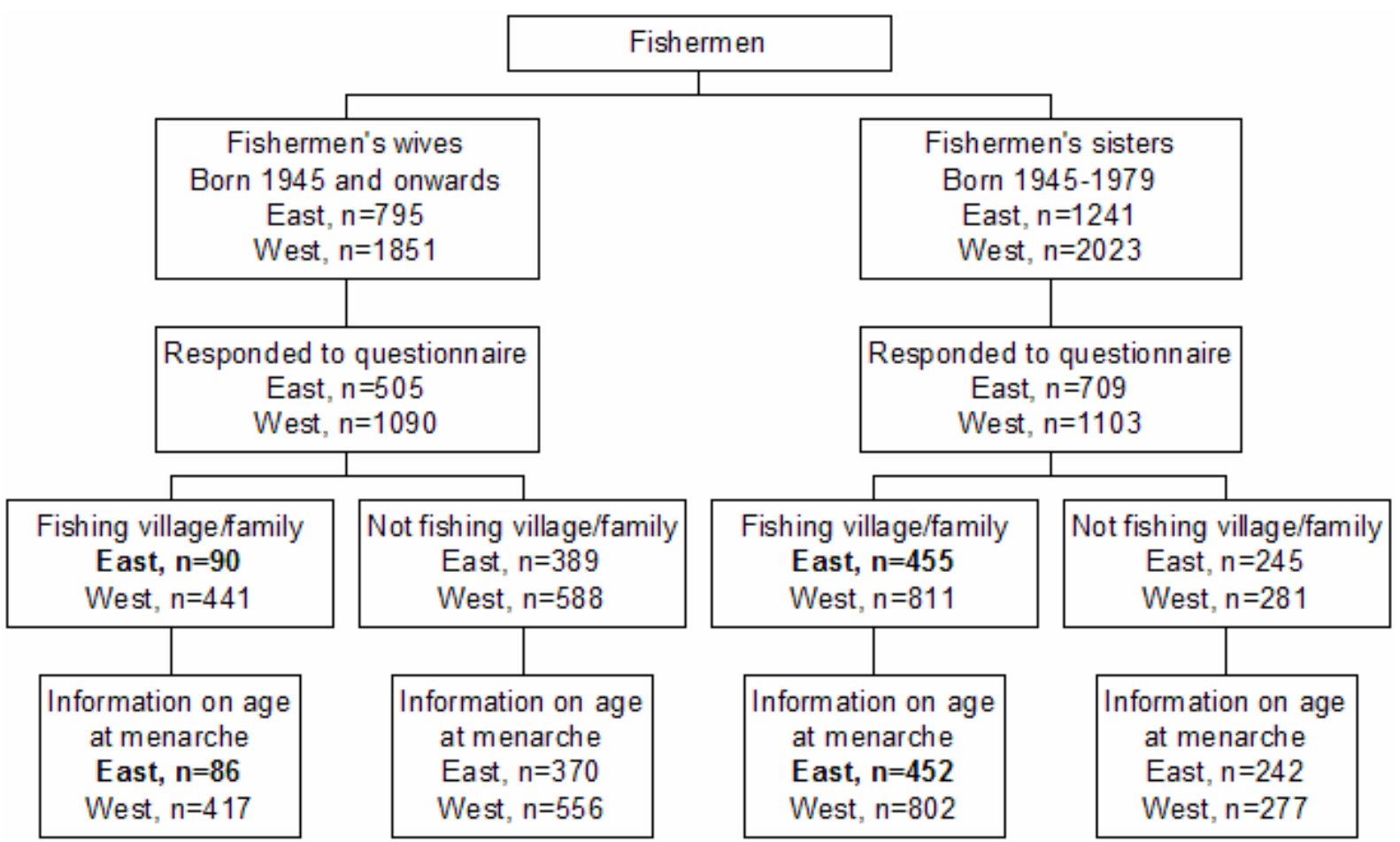

Figure 1. Flowchart of inclusion of women into a study on age at menarche and exposure to persistent organochlorine compounds (POPs). 


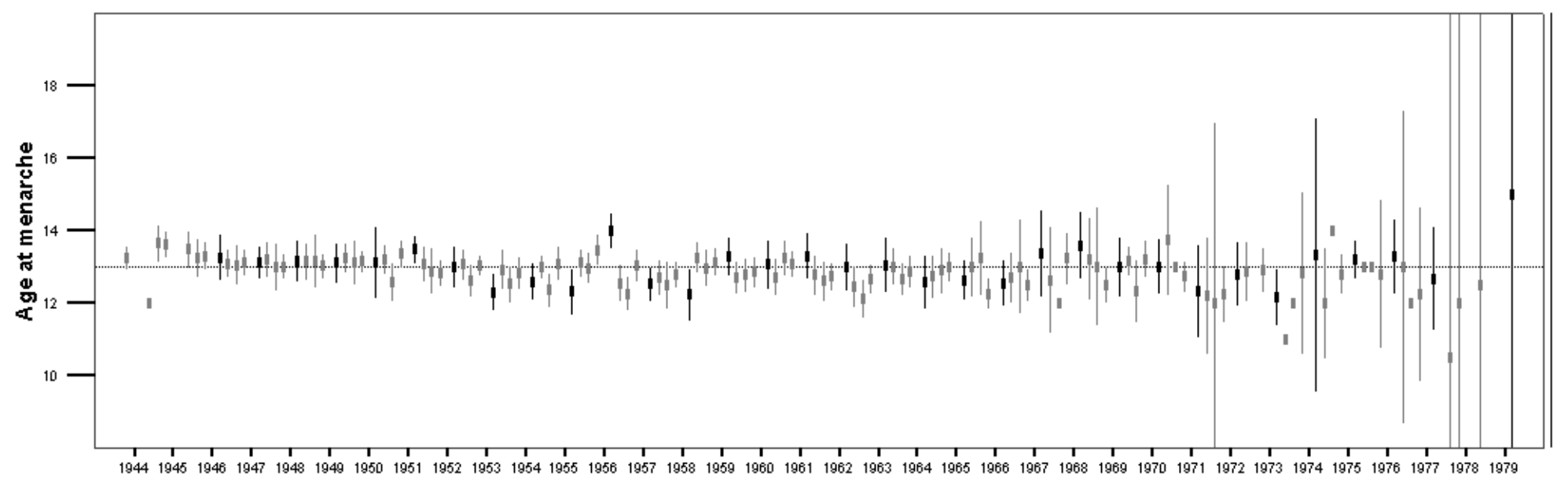

Year of birth

Figure 2. Mean age at menarche, with $95 \%$ confidence intervals, for women with high exposure to persistent organochlorine pollutants in utero and during childhood (black marks) and their referents (grey marks). The overall mean (13.0 years) is indicated by a dotted line. 